compared, talc not only causes a greater degree of apoptosis of lung cancer cells than bleomycin at equivalent concentrations, but it also demonstrates selectivity of action by sparing the normal mesothelium, which is not observed with bleomycin or doxycyline. Our in vitro observation was further supported by the discovery of a preserved layer of mesothelial cells despite an intense inflammatory pleural reaction in rabbits treated with talc [8].

Interactions between normal PMC and tumour cells are complex. An intact pleural mesothelium appears important for inciting the acute inflammatory response necessary for pleurodesis by secreting pro-inflammatory interleukin- 8 and vascular endothelial growth factor, and for developing pleural fibrosis by the production of transforming growth factor- $\beta$ and basic fibroblast growth factor [8,9]. ANTONY et al. [9] demonstrated that patients with extensive pleural carcinomatosis and minimal intervening normal mesothelium had significantly lower quantities of basic fibroblast growth factor in their pleural fluid, compared to those with limited disease who subsequently developed successful pleural symphysis. These findings suggested that a mesothelium free of tumour was necessary for successful pleurodesis [8]. A recent study also showed that an intact pleural mesothelium is critical in modulating the metastatic potential of cancer cells within the pleural space. Malignant cells secrete angiogenic factors that promote tumour growth, proliferation of endothelial cells and invasion of surrounding tissue by neovascularisation. Talc treated pleural mesothelium counteracts these effects by releasing endostatin, an antiangiogenic factor which may be responsible for tumour containment within the pleural space, and account for the improved clinical outcome of patients with malignant pleural effusions successfully pleurodesed with talc [10].

Our preliminary results support the use of talc for malignant effusion as it selectively causes apoptosis of lung cancer cells, and spares normal mesothelium pivotal for inciting inflammatory processes necessary for pleural fibrosis. Studies are underway to compare the in vitro results with in vivo response, as well as to assess the impact on patient survival.

\section{P. Lee*, L. Sun", C.K. Lim", S.E. Aw ${ }^{\#}$ and H.G. Colt}

*Depts of Respiratory and Critical Care Medicine, and "Dept of Clinical Research, Singapore General Hospital, Singapore. TPulmonary and Critical Care Medicine, UC Irvine Medical Center, Orange, CA, USA.
Correspondence: P. Lee, Dept of Respiratory and Critical Care Medicine, Singapore General Hospital, Outram Road, Singapore 169608. E-mail: lee.pyng@sgh.com.sg

Support Statement: This study was supported by a grant from the Dept of Clinical Research (Singapore General Hospital, Singapore).

Statement of Interest: None declared.

Acknowledgements: We would like to thank G. Lee (Dept of Respiratory Medicine, University of Western Australia, Perth, Australia) for his invaluable critique of the manuscript, and S. Fook (Dept of Clinical Research, Singapore General Hospital, Singapore) for her statistical input.

\section{REFERENCES}

1 Antunes G, Neville E, Duffy J, et al. BTS guidelines for the management of malignant pleural effusions. Thorax 2003; 58: Suppl. 2, ii29-ii38.

2 Shaw P, Agarwal R. Pleurodesis for malignant pleural effusions. Cochrane Database Syst Rev 2004; 1: CD002916.

3 Lee YC, Baumann MH, Maskell NA, et al. Pleurodesis practice for malignant pleural effusions in five English-speaking countries: survey of pulmonologists. Chest 2003; 124: 2229-2238.

4 Toh HC, Sun L, Koh CH, et al. Vinorelbine induces apoptosis and caspase-3 (CPP32) expression in leukemia and lymphoma cells: a comparison with vincristine. Leuk Lymphoma 1998; 31: 195-208.

5 Tan DT, Liu YP, Sun L. Flow cytometry measurements of DNA content in primary and recurrent pterygia. Invest Ophthalmol Vis Sci 2000; 41: 1684-1686.

6 Hartman DL, Gaither JM, Kesler KA, et al. Comparison of insufflated talc under thoracoscopic guidance with standard tetracycline and bleomycin pleurodesis for control of malignant pleural effusions. J Thorac Cardiovasc Surg 1993; 105: 743-747.

7 Viallat JR, Rey F, Astoul P, et al. Thoracoscopic talc poudrage pleurodesis for malignant effusions. A review of 360 cases. Chest 1996; 110: 1387-1393.

8 Marchi E, Vargas FS, Acencio MM, et al. Evidence that mesothelial cells regulate the acute inflammatory response in talc pleurodesis. Eur Respir J 2006; 28: 929-932.

9 Antony VB, Nasreen N, Mohammed KA, et al. Talc pleurodesis: basic fibroblast growth factor mediates pleural fibrosis. Chest 2004; 126: $1522-1528$.

10 Nasreen N, Mohammed KA, Brown S, et al. Talc mediates angiostasis in malignant pleural effusions via endostatin induction. Eur Respir J 2007; 29: 761-769.

DOI: $10.1183 / 09031936.00113109$

\title{
Nonresolving pneumonia and rash in an adult: pulmonary involvements in Kawasaki's disease
}

\section{To the Editors:}

Slowly resolving or nonresolving pneumonia is a challenge for physicians. The most common clinical error when approaching these patients is to subsequently treat the patient with different antibiotics over an extended period of time, without questioning the cause of treatment failure. Mostly, slowly resolving pneumonias are due to host defence or infectious causes. Nonresolving pneumonias are usually of noninfectious origin and, in the majority of cases, require invasive diagnostic 

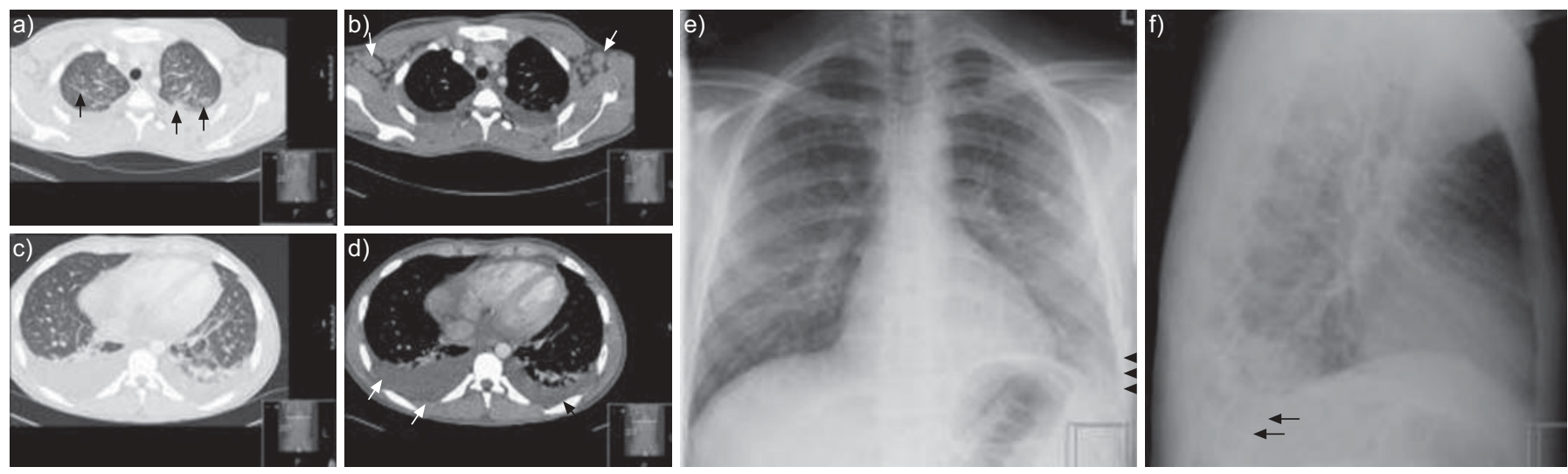

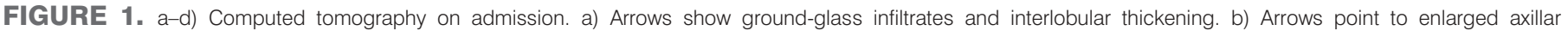

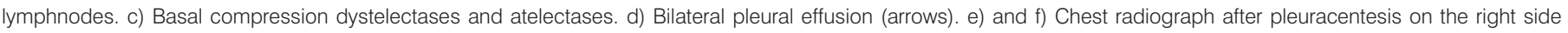
(1.5 $\mathrm{L}$ recovery). Note the left-sided effusion (arrows) and the reticulo-nodular bilateral patchy infiltrates.

techniques to be confirmed. Nonresolving or slowly resolving pneumonia should direct the clinician to a critical re-evaluation of the possible causes of the disease.

A 19-yr-old male without known comorbidity reported to a general practitioner with fever, headache, sore throat and diarrhoea. A few days later, after being treated with amoxicillin/clavulanate, he developed a generalised erythema and rash, starting on the abdomen. Already severely impaired, he later went to a primary care centre. Based on his dermatological alterations, staphylococcal toxic shock syndrome was suspected and antibiotics where changed to

\begin{tabular}{|c|c|c|}
\hline & Values & Normal range \\
\hline \multicolumn{3}{|l|}{ Red blood parameters } \\
\hline Erythrocytes $\mathrm{g} \cdot \mathrm{L}^{-1}$ & 3.49 & $4.2-5.7$ \\
\hline Haemoglobin $\mathrm{g} \cdot \mathrm{L}^{-1}$ & 106 & $135-168$ \\
\hline Thrombocytes $\mathrm{g} \cdot \mathrm{L}^{-1}$ & 431 & $140-380$ \\
\hline \multicolumn{3}{|l|}{ White blood count } \\
\hline Leukocytes $\mathrm{g} \cdot \mathrm{L}^{-1}$ & 12.1 & $3.5-10.5$ \\
\hline Neutrophils $\mathrm{g} \cdot \mathrm{L}^{-1}$ & 10.53 & $1.6-7.4$ \\
\hline Eosinophils $\mathrm{g} \cdot \mathrm{L}^{-1}$ & 0.91 & $0.02-0.40$ \\
\hline \multicolumn{3}{|l|}{ Clinical chemistry } \\
\hline $\mathrm{CRP} m g \cdot \mathrm{L}^{-1}$ & 125 & $<5$ \\
\hline ASAT $U \cdot L^{-1}$ & 55 & $10-41$ \\
\hline ALAT $U \cdot L^{-1}$ & 57 & $5-41$ \\
\hline$\gamma \mathrm{GT} U \cdot \mathrm{L}^{-1}$ & 292 & $<60$ \\
\hline $\mathrm{LDH} U \cdot \mathrm{L}^{-1}$ & 417 & $<480$ \\
\hline Lipase $U \cdot L^{-1}$ & 270 & $7-60$ \\
\hline AP $U \cdot L^{-1}$ & 374 & $36-108$ \\
\hline NT-pro-BNP pg $\cdot \mathrm{mL}^{-1}$ & 4501 & $<63$ \\
\hline Troponin $T \mu \mathrm{g} \cdot \mathrm{L}^{-1}$ & $<0.010$ & $<0.010$ \\
\hline Creatinine $\mu \mathrm{mol} \cdot \mathrm{L}^{-1}$ & 68 & $59-104$ \\
\hline
\end{tabular}

CRP: C-reactive protein; ASAT: aspartate aminotransferase; ALAT: alanine aminotransferase; $\gamma \mathrm{GT}$ : $\gamma$-glutamyl transferase; LDH: lactate dehydrogenase; AP: alkaline phosphatase; NT-pro-BNP: N-terminal pro-brain natriuretic peptide. penicillin and clindamycin. However, the condition worsened; the patient developed dyspnoea, dry cough and bilateral reticulo-nodular infiltrates on chest radiograph. He was transferred to our university hospital because of imminent respiratory failure. On admission he was still febrile $\left(38.5^{\circ} \mathrm{C}\right)$, had generalised oedema and required $6 \mathrm{~L} \cdot \mathrm{min}^{-1}$ oxygen to achieve a saturation of $96 \%$ (arterial blood gas analysis, room air: arterial oxygen and carbon dioxide tensions 8.55 and $3.45 \mathrm{kPa}$, respectively, and $\mathrm{pH}$ 7.491). On physical examination crackles were noted on lung auscultation, along with bi-basal dullness to percussion of the thorax. Additionally, bilateral conjunctival injections, cervical and axillary lymphadenopathy and markedly reddened pharynx were observed. Chest radiography and a subsequent computed tomography scan revealed massive bilateral pleural effusions with bilaterally disseminated patchy infiltrates and ground-glass alterations, modest pericardial effusion and enlarged axillary and mediastinal lymph-nodes (fig. 1). Laboratory findings showed elevated Creactive protein, slightly elevated transaminases, $\gamma$-glutamyl transferase and alkaline phosphatase and a massively elevated N-terminal pro-brain natriuretic peptide (NT-pro-BNP). Additionally, leukocyte count was $12.1 \mathrm{~g} \cdot \mathrm{L}^{-1}(87.0 \%$ neutrophil count), and thrombocytosis and anaemia were present (table 1). Based on the initial assumption of progressive, therapy refractory pneumonia, clindamycin was halted and therapy was changed to piperacillin/tazobactam and clarithromycin at standard doses. However, the previously noted maculo-squamous exanthema was progressive and he developed palmo-plantar desquamations. He remained febrile and serological markers of infections continued to be elevated. All serological and rheumatological analyses, as well as microbiology (including Legionella spp., Mycoplasma, Chlamydia spp., typical and atypical mycobacteria) and virology (Epstein-Barr virus, cytomegalovirus, parvovirus B19 and HIV), from all sampled sites (pleural effusion, blood, pharyngeal swab, sputum, urine and cerebrospinal fluid), were negative for pathogenic specimens. The next diagnostic step would have been bronchoscopy including bronchoalveolar lavage. However, the patient's condition was too marginal to allow for bronchoalveolar lavage without the risk of intubation and mechanical ventilation. 
As no infectious aetiology could be established and the patient fulfilled the major criteria for the diagnosis of Kawasaki's disease, antibiotic treatment was withdrawn and high-dose intravenous immunoglobulins at a dose of $2.0 \mathrm{~g}$ per $\mathrm{kg}$ bodyweight and acetylsalicylic acid were administered. The patient remained febrile for $>30 \mathrm{~h}$ after administration of the first dose of i.v. immunoglobulins; thus, a second dose was given, according to the American Heart Association's statement on the management of Kawasaki's disease [1]. Thereafter, the patient was finally afebrile. Echocardiography showed normal ventricular size and function without regional alterations. In adults, smaller aneurysms might be overlooked, even by experienced examiners [2], and the patient had significantly elevated NT-pro-BNP levels on admission, which gave cause to a careful examination of the heart. Therefore, coronary angiography was performed before the patient was discharged, and showed neither vascular abnormalities nor coronary artery disease. Left ventricular function was normal.

At the first follow-up visit, 1 month after discharge, the patient had fully recovered. Clinically, echocardiographically and radiographically, no residues were noted.

Kawasaki's disease is an acute febrile illness generally afflicting children in early childhood, with $\sim 80 \%$ of cases occurring between the ages of 6 months and 5 yrs [3]. It is a self-limited vasculitis of unknown aetiology, characterised by fever lasting at $\geqslant 5$ days and a constellation of clinical features that are used as diagnostic criteria. These comprise, apart from fever, polymorphous rash, nonpurulent conjunctivitis, inflammatory changes of the lips and oral cavity, oedema of hands and feet and/or redness of palms and soles, and cervical lymphadenopathy [1]. Five of these six criteria must be present, otherwise coronary aneurysms must be demonstrated [4]. In our patient, all six clinical criteria were present during the course of the disease.

Up to $20-25 \%$ of all Kawasaki's disease patients develop coronary artery aneurysms and almost $50 \%$ of all patients show mild diffuse dilatation of coronary arteries [3, 4]. Pulmonary symptoms are not frequent and are likely to be misinterpreted as atypical pneumonia, especially if they are predominant and occur in a young adult, as in the present case. Only a few, primarily paediatric, cases of pulmonary involvement in Kawasaki's disease have been reported up to now. UMEZAWA et al. [5] described pulmonary involvement in $14.7 \%$ of 129 patients with Kawasaki's disease. Occasionally, cases of Kawasaki's disease as the cause of "unresolving pneumonia" are reported [6-8]. UzIEL et al. [7] reported the cases of two children diagnosed with lobar consolidation and febrile illness which turned out to be caused by Kawasaki's disease. In 2002, VoYNOw et al. [8] described the case of a 6-yr-old child, who had low oxygen saturation and bilateral interstitial infiltrates and pleural effusions, like the patient described here, as a rare manifestation of Kawasaki's disease.
Our case is remarkable for two reasons. First, our patient was primarily too old to be considered as having Kawasaki's disease. Secondly, predominant pulmonary involvement is rather infrequent in Kawasaki's disease. However, febrile patients with "nonresolving pneumonia" should be evaluated for Kawasaki's disease, especially in the presence of cutaneus and conjunctival abnormalities, as the development of coronary artery lesions and aneurysmata can effectively be prevented by early administration of i.v. immunoglobulins. In conclusion, our case illuminates the necessity to critically reevaluate slowly resolving or nonresolving pulmonary lesions to prevent detrimental sequelae for the patient.

\section{J. Ugi* , P.M. Lepper ${ }^{\#}$, M. Witschi ${ }^{\#}$, V. Maier*, T. Geiser ${ }^{\#}$ and S.R. Ott ${ }^{\#}$ \\ *Depts of Medicine and, and "Pulmonology, University Hospital of Bern (Inselspital), University of Bern, Bern, Switzerland.}

Correspondence: S.R. Ott, Inselspital, University Hospital of Bern (Inselspital), Dept of Pulmonology, CH-3010 Bern, Switzerland. E-mail: s.r.ott@web.de

Statement of Interest: None declared.

\section{REFERENCES}

1 Newburger JW, Takahashi M, Gerber MA, et al. Committee on Rheumatic Fever, Endocarditis and Kawasaki Disease; Council on Cardiovascular Disease in the Young; American Heart Association; American Academy of Pediatrics. Diagnosis, treatment, and longterm management of Kawasaki disease: a statement for health professionals from the Committee on Rheumatic Fever, Endocarditis and Kawasaki Disease, Council on Cardiovascular Disease in the Young, American Heart Association. Circulation 2004; 110: 2747-2771.

2 de Zorzi A, Colan SD, Gauvreau K, et al. Coronary artery dimensions may be misclassified as normal in Kawasaki disease. J Pediatr 1998; 133: 254-258.

3 Burns JC, Glodé MP. Kawasaki syndrome. Lancet 2004; 364: 533-544.

4 Harnden A, Takahashi M, Burgner D. Kawasaki disease. BMJ 2009; 338: b1514.

5 Umezawa T, Saji T, Matsuo N, et al. Chest x-ray findings in the acute phase of Kawasaki disease. Pediatr Radiol 1989; 20: 48-51.

6 Falcini F, Vitale A, La Torre F, et al. Refractory pneumonia and high fever. Lancet 2009; 373: 1818.

7 Uziel Y, Hashkes PJ, Kassem E, et al. "Unresolving pneumonia" as the main manifestation of atypical Kawasaki disease. Arch Dis Child 2003; 88: 940-942.

8 Voynow JA, Schanberg L, Sporn T, et al. Pulmonary complications associated with Kawasaki disease. J Pediatr 2002; 140: 786-787. 